Network Working Group

Request for Comments: 4386

Category: Experimental
S. Boeyen

Entrust Inc.

P. Hallam-Baker

Verisign Inc.

February 2006

\title{
Internet X.509 Public Key Infrastructure \\ Repository Locator Service
}

\section{Status of This Memo}

This memo defines an Experimental Protocol for the Internet community. It does not specify an Internet standard of any kind. Discussion and suggestions for improvement are requested. Distribution of this memo is unlimited.

Copyright Notice

Copyright (C) The Internet Society (2006).

Abstract

This document defines a Public Key Infrastructure (PKI) repository locator service. The service makes use of DNS SRV records defined in accordance with RFC 2782. The service enables certificate-using systems to locate PKI repositories.

Table of Contents

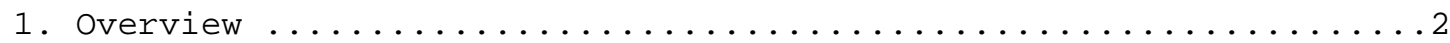

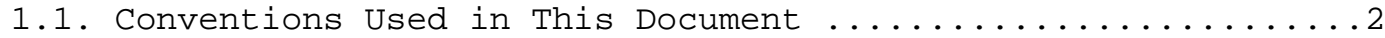

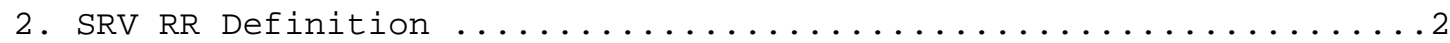

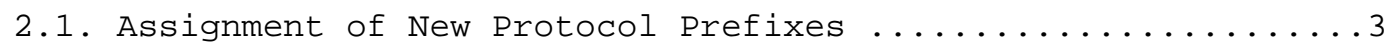

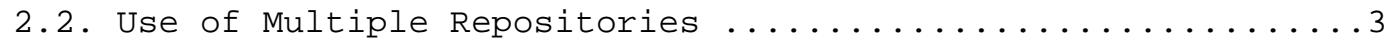

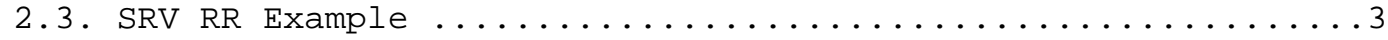

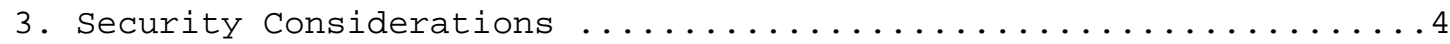

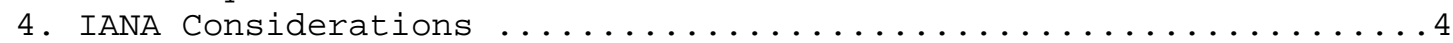

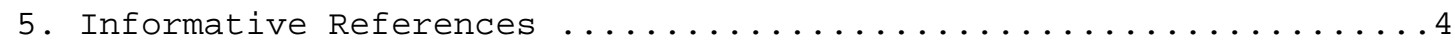




\section{Overview}

A number of RFCs (including [RFC2559], [RFC2560], and [RFC2585]) have specified operational protocols for retrieval of PKI data, including public-key certificates and revocation information, from PKI repositories. These RFCs assume that a certificate-using system has the information necessary to identify, locate, and connect to the PKI repository with a specific protocol. Although some tools are available in protocol-specific environments for this purpose, such as knowledge references in directory systems, these are restricted for use with a single protocol and do not share a common means of publication. This document provides a solution to this problem through the use of Service Record (SRV) Resource Records (RRs) in DNS. This solution is expected to be particularly useful in environments where only a domain name is available. In other situations (e.g., where a certificate is available that contains the required information), such a DNS lookup is not needed.

[RFC2782] defines a DNS RR for specifying the location of services (SRV). This document defines SRV records for a PKI repository locator service to enable PKI clients to obtain the necessary information to connect to a domain's PKI repository, including information about each protocol that is supported by that domain for access to its repository. This document includes the definition of an SRV RR format for this service and an example of its potential use in an email environment.

\subsection{Conventions Used in This Document}

The key words "MUST", "MUST NOT", "REQUIRED", "SHOULD", "ShOULD NOT", "RECOMMENDED", "MAY", and "OPTIONAL" in this document (in uppercase, as shown) are to be interpreted as described in [RFC2119].

In examples, "C:" and "S:" indicate lines sent by the client and server, respectively.

\section{SRV RR Definition}

The format of the SRV RR, whose DNS type code is 33, is: _Service._Proto.Name TTL Class SRV Priority Weight Port Target

For the PKI repository locator service, this document uses the symbolic name "PKIXREP". Note that when used in an SRV RR, this name MUST be prepended with an "_" character. 
The protocols that can be included in PKIXREP SRV RRs are:

$\begin{array}{ll}\text { Protocol } & \text { SRV Prefix } \\ \text { LDAP } & \text {-LDAP } \\ \text { HTTP } & \text { - HTTP } \\ \text { OCSP } & \text { _OCSP }\end{array}$

\subsection{Assignment of New Protocol Prefixes}

Protocol prefix assignments for new PKIX repository protocols SHOULD be defined in the document that specifies the protocol.

\subsection{Use of Multiple Repositories}

The existence of multiple repositories MAY be determined by making separate DNS queries for each of the protocols supported by the client.

If this approach is found to be unacceptably inefficient due to a proliferation of repository protocols at a future date, the service discovery protocol could be extended to allow the repository to advertise the protocols supported.

\subsection{SRV RR Example}

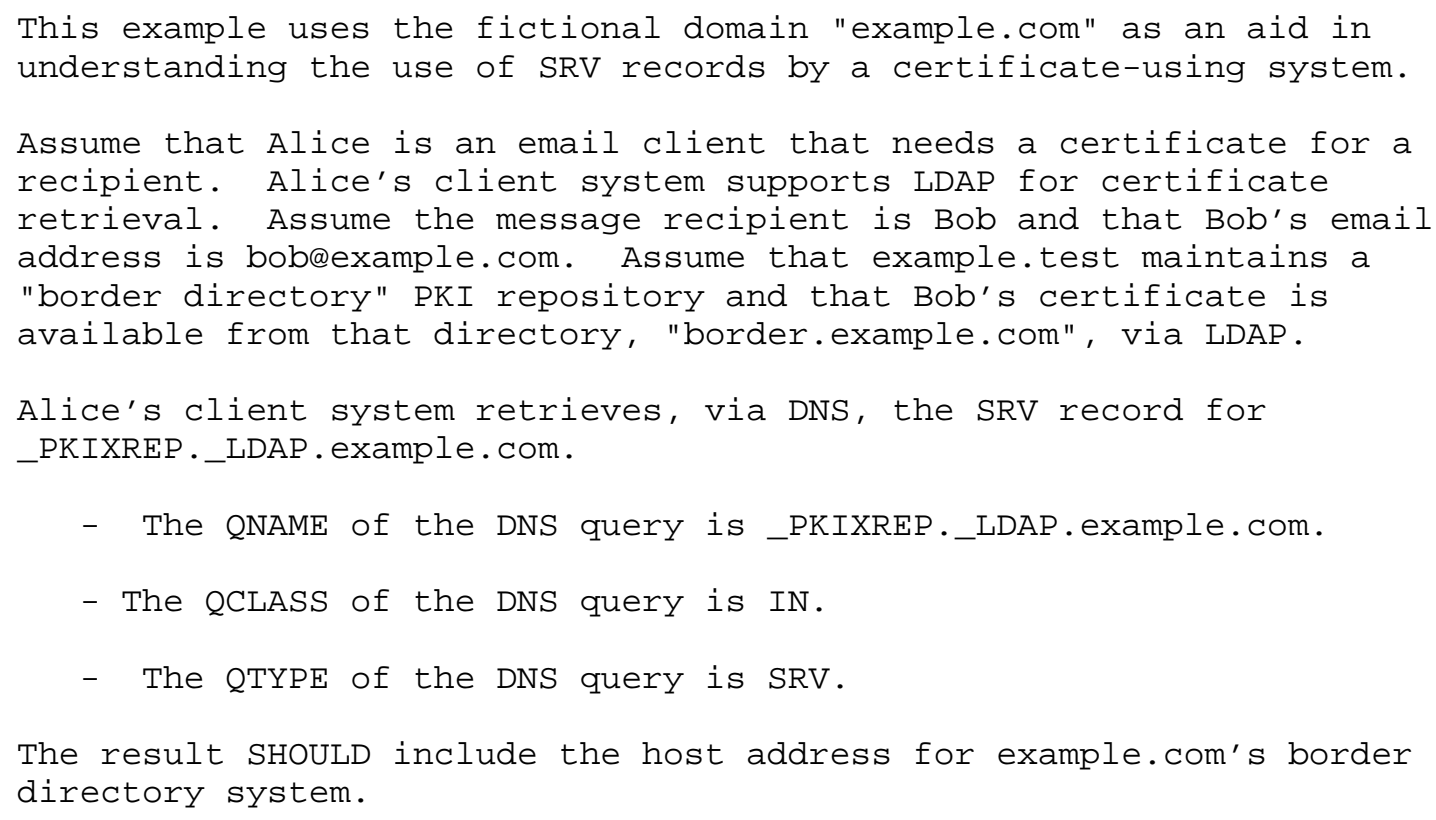


Note that if example.com operated its service on a number of hosts, more than one SRV RR would be returned. In this case, RFC 2782 defines the procedure to be followed in determining which of these should be accessed first.

\section{Security Considerations}

Security issues regarding PKI repositories themselves are outside the scope of this document. For LDAP repositories, for example, specific security considerations are addressed in RFC 2559.

Security issues with respect to the use of SRV records in general are addressed in RFC 2782, and these issues apply to the use of SRV records in the context of the PKIXREP service defined here.

4. IANA Considerations

This document reserves the use of "_PKIXREP" service label. Since this relates to a service that may pass messages over a number of different message transports, each message must be associated with a specific transport.

In order to ensure that the association between "_PKIXREP" and their respective underlying services is deterministic, the IANA has created a new registry: PKIX SRV Protocol Labels.

For this registry, an entry shall consist of a label name and a pointer to a specification describing how the protocol named in the label uses SRV. Specifications should conform to the requirements listed in [RFC2434] for "specification required".

5. Informative References

[RFC2119] Bradner, S., "Key words for use in RFCs to Indicate Requirement Levels", BCP 14, RFC 2119, March 1997.

[RFC2434] Narten, T. and H. Alvestrand, "Guidelines for Writing an IANA Considerations section in RFCs", BCP 26, RFC 2434, October 1998 .

[RFC2559] Boeyen, S., Howes, T., and P. Richard, "Internet X.509 Public Key Infrastructure Operational Protocols - LDAPv2", RFC 2559, April 1999.

[RFC2560] Myers, M., Ankney, R., Malpani, A., Galperin, S., and C. Adams, "X.509 Internet Public Key Infrastructure Online Certificate Status Protocol - OCSP", RFC 2560, June 1999. 
[RFC2585] Housley, R. and P. Hoffman, "Internet X.509 Public Key Infrastructure Operational Protocols: FTP and HTTP", RFC 2585, May 1999.

[RFC2782] Gulbrandsen, A., Vixie, P., and L. Esibov, "A DNS RR for specifying the location of services (DNS SRV)", RFC 2782, February 2000 .

\author{
Authors' Addresses \\ Sharon Boeyen \\ Entrust \\ 1000 Innovation Drive \\ Ottawa, Ontario \\ Canada K2K $3 E 7$ \\ EMail: sharon.boeyendentrust.com \\ Phillip M. Hallam-Baker \\ Verisign Inc. \\ 401 Edgewater Place, Suite 280 \\ Wakefield MA 01880 \\ EMail: pbakereVerisign.com
}


Full Copyright statement

Copyright (C) The Internet Society (2006).

This document is subject to the rights, licenses and restrictions contained in BCP 78, and except as set forth therein, the authors retain all their rights.

This document and the information contained herein are provided on an "AS IS" basis and THE CONTRIBUTOR, THE ORGANIZATION HE/SHE REPRESENTS OR IS SPONSORED BY (IF ANY), THE INTERNET SOCIETY AND THE INTERNET ENGINEERING TASK FORCE DISCLAIM ALL WARRANTIES, EXPRESS OR IMPLIED, INCLUDING BUT NOT LIMITED TO ANY WARRANTY THAT THE USE OF THE INFORMATION HEREIN WILL NOT INFRINGE ANY RIGHTS OR ANY IMPLIED WARRANTIES OF MERCHANTABILITY OR FITNESS FOR A PARTICULAR PURPOSE.

Intellectual Property

The IETF takes no position regarding the validity or scope of any Intellectual Property Rights or other rights that might be claimed to pertain to the implementation or use of the technology described in this document or the extent to which any license under such rights might or might not be available; nor does it represent that it has made any independent effort to identify any such rights. Information on the procedures with respect to rights in RFC documents can be found in BCP 78 and BCP 79 .

Copies of IPR disclosures made to the IETF Secretariat and any assurances of licenses to be made available, or the result of an attempt made to obtain a general license or permission for the use of such proprietary rights by implementers or users of this specification can be obtained from the IETF on-line IPR repository at http://www.ietf.org/ipr.

The IETF invites any interested party to bring to its attention any copyrights, patents or patent applications, or other proprietary rights that may cover technology that may be required to implement this standard. Please address the information to the IETF at ietf-ipreietf.org.

Acknowledgement

Funding for the RFC Editor function is provided by the IETF Administrative Support Activity (IASA). 